\title{
sciforum
}

Conference Proceedings Paper

\section{Wind erosion and factors controlling the surface composition in abandoned tailings}

\author{
Javiera Gerding ${ }^{1,2,3 *}$, Alexey Novoselov ${ }^{2}$ and Juan Morales ${ }^{3}$ \\ 1 Departamento Ciencias de la Tierra, Universidad de Concepción, Concepción, Chile \\ 2 Institute of Applied Economic Geology, Universidad de Concepción, Concepción, Chile \\ 3 Departamento de Geología, Cristalografía y Mineralogía, Universidad de Salamanca, Salamanca \\ * Correspondence: javigerding@gmail.com \\ Received: date; Accepted: date; Published: date
}

\begin{abstract}
Chile has developed its mining industry for decades, mainly in the north of the country, where arid climates dominate. Many of these tailings have been abandoned to the weather. The evaluation of what happens at the surface of abandoned tailings, depending on the dominant mineralogy and climate, will be critical in assessing potential impacts from wind erosion or reworking of these deposits.

Two areas of study with different climates ranging from arid to semi-arid were evaluated by mineralogy, chemistry and particle size. Using statistical analysis, it was possible to establish different types of sediments, which mainly differed in secondary mineralogy, giving rise to three clusters. When observing these clusters in the field, different surfaces can be observed, in terms of their cohesion and wind erodibility potential. The mineralogical analysis of each cluster in both climates show that although the surfaces of the deposits are similar, the particle size, amount of pyrite and other phases vary from one site to another.

From the characterization of these sites, it is evident that pyrite alone will not generate acidic solutions that lead to the precipitation of secondary phases. These secondary phases will be linked to the climate (meaning available humidity), particle size and quantity of pyrite present and neutralising phases. Depending on these variables, different potentially erodible surfaces will be generated, which will lead to a greater or lesser cohesion of particles and different metal contents which is, in turn, the reason for these tailings to become a public health issue.
\end{abstract}

Keywords: tailings, pyrite, arid \& semi-arid climate, wind erosion, Chile.

\section{Introduction}

Developments in the metallurgical industry, coupled with an increased demand for metals, have led to the review of old mine tailings for reuse [1-4]. Otherwise, those of no economic interest are often left without remediation at the disposal of the climate and the surrounding population. Particle transport by wind is one of the most powerful carriers of pollutants, with mineralogy, grain size and climate being the most important influencing factors [5-7].

Their fine grain size $(<400 \mathrm{um})$ together with the presence of sulphides in tailings, are important characteristics that will lead to important changes in their mineralogy [5,8-9]. Sulphides, in the presence of oxygen and water, oxidise releasing sulphate anions $\left(\mathrm{SO}_{4}^{-2}\right)$ and $\mathrm{Fe}^{+3}[10,11]$. This oxidation and subsequent dissolution of sulphides leads to the release of metals and metaolides, which can constitute a risk to the community and the environment [12-14].

Tailings in northern Chile provide an excellent opportunity to study the relationship between climatic factors and mineralogy and their effects on windblown dust. There are more than 740 tailings in Chile, $80 \%$ of which are under arid and semi-arid climatic conditions, and $77 \%$ of which are inactive 
or abandoned [15]. In these climatic conditions, the action of the wind on the surfaces is predominant, since there is little vegetation due to scarcity of water $[5,16]$.

The main objective of this work is to evaluate how the mineralogical evolution of unremediated tailings in arid and semi-arid climates can affect potential wind-dust emissions. To pursue this objective, we analysed the mineralogy, chemistry and particle size distribution of surface and deepseated materials in the tailings.

\section{Materials and Methods}

A total of 98 samples were collected from the Domeyko (-28.956168, -70.886112) and Delirio ($30.878823,-71.240821)$ tailings deposits, located in arid and semi-arid climates respectively. Both study sites have no deposit remediation and have been without operations for at least 20 years.

The sampling consisted of soil pits in a regular mesh of $20 \mathrm{~m}$, for both tailings, with a depth of $50 \mathrm{~cm}$. In each soil pit, three samples of 5 to $10 \mathrm{~kg}$ each were taken: (i) from the uppermost tailings layer of 0-2 cm, (ii) at a depth of $20 \mathrm{~cm}$, and (iii) at a depth of $50 \mathrm{~cm}$.

Mineralogy of the samples was performed by X-ray diffraction (XRD, Bruker D4 Endeavor), automated optical microscopy (SIAMS®) with reflected light and automated mineralogy (QEMSCAN®), while chemistry was performed by X-ray fluorescence (XRF, Rigaku ZSX Primus II). Particle size distribution of the samples was performed by laser diffraction on the Fritsch Analysette 22 Microtec Plus, operated with ultrasonic scattering.

The statistical handling was conducted in R 4.0.0 (R Core Team, 2017) using RStudio software version 1.2.5042. We tabulated all chemical, mineralogical and granulometric parameters (53 in total) in the Microsoft Excel dataset. First, we selected 30 most reliable and complete variables avoiding parameters with a strong cross-correlation. To outline relationships between variables, we plotted a correlogram. Then, using the FactoMineR package version 2.3 [17], we made a principal component analysis (PCA). To proceed with the correct breakdown of collected tailings samples $(\mathrm{n}=98)$, we can consider no more than $\mathrm{m}=6$ clustering variables $(\mathrm{n}>2 \mathrm{~m}-[18])$. Therefore, we adopted first six principal components resulted by PCA. Those principal components explain $77 \%$ of variance in the dataset. We implemented the hierarchical clustering on principal components by means of the HCPC function [17]. The HCPC function computes the Euclidean distances between normalized parameters of the samples and applies the Ward's agglomeration method to construct a hierarchical dendrogram. The number of clusters was selected using the criterion on the growth of within cluster inertia. The minimal number of clusters should correspond to the greater gain of inertia within them [17]. Thus, three clusters were outlined and plotted to the factor map of two first principal components.

\section{Results}

Both study areas are dominated by $\mathrm{SiO}_{2}$ and $\mathrm{Fe}_{2} \mathrm{O}_{3}$, with variations in $\mathrm{Al}_{2} \mathrm{O}_{3}, \mathrm{CaO}$ and $\mathrm{SO}_{3}$. In Delirio tailings, $\mathrm{SiO}_{2}$ and $\mathrm{CaO}$ remain relatively stable in both sectors ( $\mathrm{SiO}_{2}: 50.15$ wt.\% in DR_E and 53.4 in DR_W; CaO: 8.04 wt.\% in DR_E and 5.6 wt.\% in DR_W), while $\mathrm{Fe}_{2} \mathrm{O}_{3}$ and $\mathrm{SO}_{3}$ dominate in DR_E (22.1 wt.\% and 16.0 wt.\%, respectively) with respect to DR_W (15 wt.\% Fe2 $\mathrm{O}_{3}$ and 0.74 wt.\% $\left.\mathrm{SO}_{3}\right)$ and $\mathrm{Al}_{2} \mathrm{O}_{3}$ dominates in DR_W (14.9 wt.\%). Domeyko tailings show similarities in DK_Old and DK_90 in $\mathrm{Fe}_{2} \mathrm{O}_{3}$ and $\mathrm{Al}_{2} \mathrm{O}_{3}$, while $\mathrm{SiO}_{2}$ is more abundant in DK_Old than in DK_90 (60.15 wt.\% and 36.8 wt.\% respectively) and $\mathrm{SO}_{3}$ and $\mathrm{CaO}$ show higher values in DK_90 (19.7 wt.\% and 8.0 wt.\% respectively). There are differences in the heavy metals content, the Delirio tailings are dominated by $\mathrm{Cu}$ and $\mathrm{Co}$ (an average of $0.67 \mathrm{wt} \%$ and 0.06 wt.\%, respectively) and traces of As, Zn and Sb, while the Domeyko tailings show high values of $\mathrm{Pb}, \mathrm{As}, \mathrm{Cu}$ and $\mathrm{Zn}$.

The Delirio tailings can be subdivided into 2 portions: Delirio West (DR_W) and Delirio East (DR_E).These differ mainly in mineralogy, because DR_W has a higher amount of silicates: quartz (an average of $30.8 \mathrm{wt} . \%$ ), white micas (23.8), plagioclase (20.7), chlorite (7.1), orthoclase (3.9) and amphibole (3.8), without the presence of secondary mineralogy. While DR_E shows sulphate 
development (gypsum (5.9) and jarosite (3.4)), abundant quartz (69.4), epidote (8.4) and higher percentage of pyrite (6.2) than DR_W (0.3),

The older section of Domeyko (DK_Old) is mainly composed of quartz (69.5 wt.\%), with lesser amounts of chlorite (8.9), white micas (8.2), pyrite (3.2) and calcite (2.2) as primary phases, and gypsum (3.5), goethite (1.3), hematite (1.3) and jarosite (quite locally) as secondary minerals. The samples collected from the latter tailings (DK_90) present more varied mineralogy that goes from samples rich in quartz and pyrite, to others rich in feldspars, pyrite, calcite and quartz.

\subsection{Statistical Analysis}

The principal component analysis and hierarchical clustering revealed three well-defined clusters in collected data (Fig. 1). Both Domeyko and Delirio tailing deposits include the samples attributed to each of the clusters. Basing on the main mineralogical features of clusters predicted by statistical tests, we entitled them as clusters of Feldspar, Goethite and Jarosite. The samples of Goethite cluster are more typical for Domeyko tailings, while Delirio dominates in Feldspar and Jarosite clusters. The differences between the superficial layer $(2 \mathrm{~cm})$ and the deeper horizons $(20$ and $50 \mathrm{~cm}$ ) show a general shift from Feldspar toward Jarosite cluster at tailings surface. This observation can be explained by plagioclase dissolution and losses by wind and accumulation of the secondary sulfates in the uppermost level. It is worth mentioning that pyrite content of does not play a decisive role in this clustering, although it is closer to the group composed of jarosite. The pyrite content is distributed in all the groups defined below.
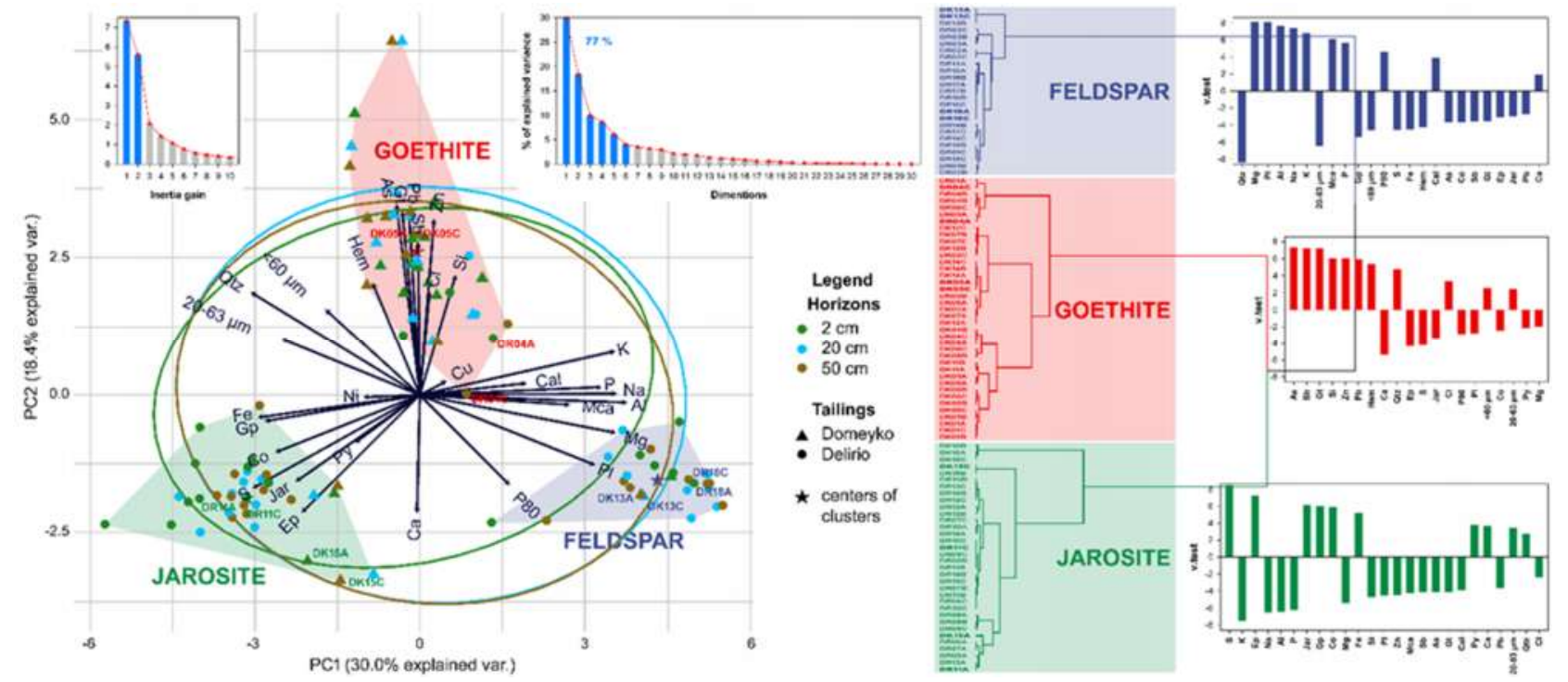

Fig. 1. The principal component analysis and hierarchical clustering of collected samples by means of chemical, mineralogical and granulometric parameters. The supplementary vertical bar charts express the selection of the number of clusters by the inertia gain, the number of principal components used for the clustering and the scores of v.test for each cluster. The paragon samples are entitled in the factor map and bolded in the dendrogram. Abbreviations for minerals: Cal - calcite, Ep - epidote, Gp - gypsum, Gt - goethite, Hem - hematite, Jar - jarosite, $\mathrm{Mca}$ - mica, Pl - plagioclase, Py - pyrite, Qtz - quartz.

\subsubsection{Clusters}

Feldspar Cluster. Although these samples are found in both study areas, they are more characteristic of the Delirio tailings, western section (DR_W). They are characterized as non-cohesive particles and show ripples as wind erosion structures on them. In terms of mineralogy, they present plagioclase, orthoclase, white mica and, to a lesser extent, amphibole, chlorite and calcite, without presenting sulphates or Fe oxides. They are associated with lithophile elements, such as $\mathrm{Na}, \mathrm{Mg}, \mathrm{Al}, \mathrm{P}, \mathrm{Ti}$ and Sr. 
Goethite Cluster. Like the previous group, samples from both deposits are also found in this group, with samples from DK_old (arid) and DR_W (semi-arid). However, here the particles are moderately cohesive, with no morphological features of wind action. The main mineralogy is represented by goethite, hematite, chlorite and, to a lesser extent, gypsum. They also correlate with elements such as $\mathrm{V}, \mathrm{Zn}, \mathrm{As}, \mathrm{Sb}, \mathrm{Pb}$ and $\mathrm{Bi}$, and correlate well with the finer particles $(<60 \mu \mathrm{m}$ and $<20 \mu \mathrm{m})$.

Jarosite Cluster. This group is present in both study sites, although it is more developed in the Delirio tailing, East section (DR_E). At the latter site, the samples are characterized by the presence of efflorescent salts of the Copiapita, Coquimbita and Alunogen groups, intermittently on the surface of the deposit. Due to these salts, the particles show good cohesion, with no morphology attributable to wind erosion. Characteristic mineralogy are sulphates (jarosite and gypsum), epidote, pyrite and, less abundant, magnetite. In addition, the eigenvectors plotted reveal a good correlation between $\mathrm{Fe}$, $\mathrm{S}$ and Co.

\subsection{Mineralogy, chemistry and particle size distribution of tailings by selected clusters}

The mineral phase distribution does not show any trend as a function of the climate. It is interesting to note that pyrite presents an accumulation at shallow levels in every cluster, with an accumulation 2 times higher on surfaces of the Jarosite cluster in semiarid climate.

The XRF analyses show no trends in the elements according to their depth. However, the Jarosite cluster in $\mathrm{DK}$ shows a significant increase in $\mathrm{Na}, \mathrm{S}, \mathrm{Cl}, \mathrm{Pb}$ and As at surface. The same cluster, in the section that develops efflorescent salts (semi-arid climate), also shows an increase in surface elements ( $\mathrm{Na}, \mathrm{Mg}, \mathrm{Cl}$ and $\mathrm{Co}$ ).

Regarding the particle size in the clusters, it is observed that there is an increase in fine particles (<60um) towards the surface in the semi-arid climate samples. This is not the case in the arid climate samples, where the Jarosite cluster shows the opposite, with a decrease in fine particles at the surface, and the Goethite cluster shows no variation with respect to these.

\subsection{Morphological Analysis in Pyrite}

Electron microscopy analysis of pyrite particle release shows differences in pyrite association with other phases in both climates studied. In arid climate, pyrite is observed with more liberated edges, without contact with other mineral phases. By contrast, in semi-arid climate, most of the pyrite particles are associated with other phases. Jarosite and Fe oxides/hydroxides are the phases that usually occlude pyrite grains, as a result of their substitution due to oxidation of the primary phase.

With regard to particle shape, observed under the optical microscope, it was observed that surface samples from the semi-arid climate have fewer circular particles than those from the arid climate. This circularity in the surface particles reflects the effect of wind erosion. All clusters in both climates had more circular pyrite particles at surface than at depth, being more evident in the Feldspar cluster, where there is evidence of wind erosion at surface. The only exception is the DR_E samples covered the salt crust (jarosite cluster at Delirio), where more rounded particles are present at depth.

\section{Discussion}

Exposing unremediated tailings to variable climatic conditions will undoubtedly drive mineralogical, chemical and physical changes of the particles, especially with the presence of sulphides and its by-products due to its oxidation. These changes will influence the evolution of the tailings surface and consequently the emission of particles by wind erosion.

Analysis of surface morphologies in the field show that there are important differences in the cohesion of the particles, which can influence wind erosion. The low particle cohesion is linked to the lack of development of secondary mineralogy, as observed in the feldspar cluster. The group represented by Goethite, presents moderate particle cohesion, which is cemented by iron oxides and hydroxide. Finally, we observe highly cohesive materials, present in the jarosite cluster, where the 
formation of efflorescent salt crusts dominates. Dust emission from the tailings surfaces can be deduced from the complex comparison of changes in mineral composition and grain size.

The feldspar-dominated cluster shows low reactivity at both study sites. At Delirio it may be related to the absence of pyrite (less than 1\%). In contrast, at Domeyko the original pyrite content of $15 \mathrm{wt} . \%$ is significant, however, the pyrite grains are weakly corroded. The larger grain size in this section of the cluster may be related to its low corrosion, due to the higher permeability involved and its low specific reactive surface area $[10,20]$. As mentioned above, the samples from this cluster have very low particle cohesion in the field. This particularity makes them more susceptible to wind erosion. At Domeyko, the samples from this cluster show larger particle size and greater circularity on the surface, as well as a decrease in pyrite content. This demonstrates the wind action and the emission of sulphide-bearing dust. In the case of this group at Delirio, the mineralogy shows an emission of mainly silicates.

The goethite-dominated group is characterized by a slightly acidic $\mathrm{pH}$ and a finer grain size. The pyrites of this cluster at Delirio show clear dissolution under the microscope, especially at deeper levels. In contrast, the pyrites at Domeyko, show a low corrosion rate and rims of iron oxides and hydroxides under the microscope. These differences in pyrite dissolution show that we can develop this type of mineral association (cluster) either because of a low amount of pyrite or because of a weak oxidation of pyrite due to water scarcity $[11,19]$. Nevertheless, if we compare the data between upper and lower levels, we see that this cluster is the one with the lowest variability. This can be translated as less dust release from the surface. Particles that could be wind-eroded are dominated by chlorite, iron oxide-hydroxide, white mica, biotite and quartz.

The jarosite cluster is mainly characterized by the presence of sulphates (jarosite and gypsum) and a significant development of efflorescent salts of the Coquimbite, Copiapite and Alunogen groups, which can be attributed to the evaporation-dominated scenario proposed by Dold (2001) [20]. The humidity of the semi-arid climate together with the presence of pyrite $(6 \mathrm{wt} . \%)$ and the absence of acid neutralizing minerals, make the eastern Delirio a potential generator of acidic waters [21-22]. The Domeyko samples, despite having a high amount of pyrite (27 wt.\%) and low concentration of neutralizing minerals, do not exhibit efflorescent salts on the surface, mainly due to the scarcity of water, which is essential for the development of salt crusts in arid areas [7].

In Jarosite cluster, in both tailings, an increase of pyrite is observed towards the surface samples, which could be related to a mechanical concentration due to wind erosion. In relation to the size of the particles, it is observed that in Domeyko those in the 20-63 um range would be more susceptible to emission. Contrary to Delirio, where the samples from this cluster show an increase in particles in this range on the surface, which would be captured by the development of sulphate crusts. Several authors [6, 23-24] propose that the aeolian erosion of these surface-generated crusts would present higher particle emission, due to their fine grains and low density. In addition, these eroded particles may have a greater impact on the surrounding environment and community due to their high solubility and bio-dissolvability [19, 25].

The processing of our data, with respect to gains and losses in mineralogy and particle size of jarosite cluster, shows that it is the most prone to mineralogical changes at the surface, which can be interpreted as a result of wind erosion. However, the high cohesion of the particles in the field and the low circularity of the particles at the surface contradict this interpretation. Nield et al. (2016) [26] evaluated sediment erosion with salt crust generation in a wind tunnel and determined that this process occurs without the saltation step. This last study could explain the low circularity of the particles in this group and the absence of typical erosion morphologies, such as ripples. Additionally, Buck et al. (2011) [27] noted that these crusts are more emissive in the early stages of crystallization, when they are less cohesive and the crystals are smaller. 


\section{Conclusions}

Detailed characterization of the particles that constitute mine tailings can provide us with information about their possible surface evolution depending on the climate in which the deposits are located. The data analyzed in this research provide three possible evolutions that can occur in tailings: no secondary alterations (feldspar cluster), low reactive sectors (goethite cluster) and highly reactive sites (jarosite cluster). In relation to dust emission, the goethite-dominated surfaces would release the least amount of particles into the air, while the jarosite cluster would emit the highest losses. From an environmental impact perspective, the samples from the goethite cluster may have a higher distribution of potentially toxic elements, due to the relationship with these at the time of their precipitation, while the surfaces of the jarosite cluster emit these elements in the form of soluble salts, making these tailings sectors the most harmful to the population and the environment.

\section{References}

1. Andrews, W.J., Moreno, C.J.G., Nairn, R.W., 2013. Potential recovery of aluminum, titanium, lead, and zinc 2. Hammas-Nasri, I., Horchani-Naifer, K., FÃ@rid, M., Barca, D., 2016. Rare earths concentration from phosphogypsum waste by two-step leaching method. International Journal of Mineral Processing 149, 78-83. from tailings in the abandoned Picher mining district of Oklahoma. Mineral Economics 26, 61-69.

3. Lottermoser, B.G., 2011. Recycling, Reuse and Rehabilitation of Mine Wastes. Elements 7, 405-410.

4. Lutandula, M.S., Maloba, B., 2013. Recovery of cobalt and copper through reprocessing of tailings from flotation of oxidised ores. Journal of Environmental Chemical Engineering 1, 1085-1090.

5. Csavina, J., Field, J., Taylor, M.P., Gao, S., Landázuri, A., Betterton, E.A., Sáez, A.E., 2012. A review on the importance of metals and metalloids in atmospheric dust and aerosol from mining operations. Science of the Total Environment 433, 58-73.

6. Meza-Figueroa, D., Maier, R.M., O-Villanueva, M.d.l., Agustín Gómez-Alvarez, Moreno-Zazueta, A., Rivera, J., Campillo, A., Grandlic, C.J., Ricardo Anaya, Palafox-Reyes, J., 2009. The impact of unconfined mine tailings in residential areas from a mining town in a semi-arid environment: Nacozari, Sonora, Mexico. Chemosphere 77, 140-147.

7. Redwan, M., Rammlmair, D., 2012. Influence of climate, mineralogy and mineral processing on the weathering behaviour within two, low-sulfide, high-carbonate, gold mine tailings in the Eastern Desert of Egypt. Environ Earth Sci 65, 2179-2193

8. Kossoff, D., Dubbin, W.E., Alfredsson, M., Edwards, S.J., Macklin, M.G., Hudson-Edwards, K.A., 2014. Mine tailings dams: Characteristics, failure, environmental impacts, and remediation. Applied Geochemistry 51, 229245.

9. Kargbo, D.M., Chatterjee, S., 2005. Stability of Silicate Coatings on Pyrite Surfaces in a Low pH Environment. Journal of Environmental Engineering 131, 1340-1349.

10. Wang, H., Dowd, P.A., Xu, C., 2019. A reaction rate model for pyrite oxidation considering the influence of water content and temperature. Minerals Engineering 134, 345-355.

11. León, E.A., Rate, A.W., Hinz, C., Campbell, G.D., 2004. Weathering of sulphide minerals at circum-neutral$\mathrm{pH}$ in semi-arid/arid environments: influence of water content, SuperSoil. University of Sydney, Australia.

12. Giuliano, V., Pagnanelli, F., Bornoroni, L., Toro, L., Abbruzzese, C., 2007. Toxic elements at a disused mine district: Particle size distribution and total concentration in stream sediments and mine tailings. Journal of Hazardous Materials 148, 409-418.

13. Sims, D.B., Hooda, P.S., Gillmore, G.K., 2013. Mining activities and associated environmental impacts in arid climates: a literature review. Environment and Pollution 2, 22-43.

14. Yurkevich, N.V., Abrosimova, N.A., Bortnikova, S.B., Karin, Y.G., Saeva, O.P., 2017. Geophysical investigations for evaluation of environmental pollution in a mine tailings area. Toxicological \& Environmental Chemistry 99, 1328-1345

15. Sernageomin, 2018. Análisis del Catasttro de Depositos de Relave en Chile y guia de estrucutra de datos, 2018 ed, p. 13.

16. Reheis, M.C., 2006. A 16-year record of eolian dust in Southern Nevada and California, USA: Controls on dust generation and accumulation. Journal of Arid Environments 67, 487-520.

17. Husson, F., Josse, J., Pagès, J., 2010. Principal components methods - hierarchical clustering - partitional clustering: why would we need to choose for visualizing data? Agrocampus, 1-17.

18. Formann, A.K., 1984. Die Latent-Class-Analyse: Einführung in die Theorie und Anwendung. [Latent class analysis: Introduction to theory and application]. in: Weinheim, B. (Ed.). 
19. Clemente, J.S., Huntsman, P., 2019. Potential climate change effects on the geochemical stability of waste and mobility of elements in receiving environments for Canadian metal mines south of $60 \hat{\mathrm{A}}^{\circ} \mathrm{N}$. Environmental Reviews, 1-41

20. Dold, B., Fontboté, L., 2001. Element Cycling and secondary mineralogy in porphyry copper tailings as a function of climate, primary mineralogy and mineral processing. Journal of Geochemical Exploration 74, 3-55.

21. Jamieson, H.E., Walker, S.R., Parsons, M.B., 2015. Mineralogical Characterization of Mine Waste. Applied Geochemistry.

22. Martinez, P., 2019. Protocolo de caracterización para la predicción de drenaje ácido en depositos de relaves mineros Universidad Internacional de Andalucía, Andalucía, España, p. 62.

23. Del Rio-Salas, R., Ayala-Ramírez, Y., Loredo-Portales, R., Romero, F., Molina-Freaner, F., Minjarez-Osorio, C., Pi-Puig, T., Ochoa-Landín, L., Moreno-Rodríguez, V., 2019. Mineralogy and Geochemistry of Rural Road Dust and Nearby Mine Tailings: A Case of Ignored Pollution Hazard from an Abandoned Mining Site in Semiarid Zone. Natural Resources Research 28, 1485-1503.

24. Sánchez Bisquert, D., Matías Peñas Castejón, J., García Fernández, G., 2017. The impact of atmospheric dust deposition and trace elements levels on the villages surrounding the former mining areas in a semi-arid environment (SE Spain). Atmospheric Environment 152, 256-269.

25. Hayes, S.M., Webb, S.M., Bargar, J.R., O’Day, P.A., Maier, R.M., Chorover, J., 2012. Geochemical weathering increases lead bioaccessibility in semi-arid mine tailings. Environ. Sci. Technol. 46, 5834-5841.

26. Nield, J.M., McKenna Neuman, C., O’Brien, P., Bryant, R.G., Wiggs, G.F.S., 2016. Evaporative sodium salt crust development and its wind tunnel derived transport dynamics under variable climatic conditions. Aeolian Res. 23, 51-62.

27. Buck, B.J., King, J., Etyemezian, V., 2011. Effects of salt mineralogy on dust emissions, Salton Sea, California. Soil Sci. Soc. Am. J. 75, 1971-1985.

Author Contributions: Javiera Gerding: Conceptualization, Methodology, Investigation, Writing - Original Draft; Alexey Novoselov: Formal analysis, Development or design of methodology; creation of models; Juan Morales: Methodology, Validation.

Funding: This research was funded by ANID for financial support Conicyt/Doctorado Nacional/2019-21181557. Acknowledgments: The laboratory staff of the GEA Institute

Conflicts of Interest: The authors declare no conflict of interest. 